\title{
ESTIMATION OF ROUNDABOUT ENTRY CAPACITY AND PASSENGER CAR EQUIVALENT FOR HEAVY VEHICLES CONSIDERING THE IMPACT OF GEOMETRIC ELEMENTS
}

\author{
Yao FANG ${ }^{1}$, Xin ZHANG ${ }^{2}$ and Hideki NAKAMURA ${ }^{3}$ \\ ${ }^{1}$ Member of JSCE, Shangcheng \& Partners \\ (Suite B 1705, City Center of Shanghai, No.100 Zunyi-road, Shanghai 200051, P.R.China) \\ E-mail: shgcjsfangyao@yahoo.co.jp \\ ${ }^{2}$ Member of JSCE, Research fellow, Graduate School of Environmental Studies, Nagoya University \\ (Furo-cho, Chikusa-ku, Nagoya 464-8603, Japan) \\ E-mail: zhang@genv.nagoya-u.ac.jp \\ ${ }^{3}$ Fellow member of JSCE, Professor, Graduate School of Environmental Studies, Nagoya University \\ (Furo-cho, Chikusa-ku, Nagoya 464-8603, Japan) \\ E-mail: nakamura@genv.nagoya-u.ac.jp
}

\begin{abstract}
Entry capacity is one of the most important indexes to evaluate the roundabout operational performance. Both the geometric elements and vehicle types have an impact on the entry capacity. Passenger Car Equivalent (PCE) for heavy vehicles is utilized for roundabout entry capacity estimation. In the Japanese Roundabout Manual (JRM), PCE is proposed as a constant value. However, it cannot reflect that the capacity of roundabouts varies with different geometric elements and heavy vehicle percentages. Therefore, the objective of this study is to estimate the PCE for heavy vehicles depending on various geometric elements. Entry capacity and PCE were estimated by the entry capacity equation in JRM and traffic simulator VISSIM, respectively. The results revealed that the entry capacity changes with different geometric elements and is significantly related to inscribed circle diameter. It was also concluded that PCE changes with increasing heavy vehicle percentages in the entering and circulating flows.
\end{abstract}

Key Words : roundabout, passenger car equivalent, heavy vehicle, geometric elements, entry capacity

\section{INTRODUCTION}

Implementing roundabouts in Japan has been promoted in recent years and the number of roundabouts is increasing due to their safety and operational performance at low to medium traffic demand levels. For evaluating the operational performance, roundabout entry capacity is one of the most important indexes. In order to improve accuracy of roundabout entry capacity estimation, influencing factors on entry capacity should be reasonably taken into account. The impact of heavy vehicles (HVs) is one of the significant factors because of their large size and slow driving speed. The roundabout geometric elements also affect HVs' driving maneuver.

Passenger car equivalent (PCE) for HVs, which represents the number of passenger cars displaced by each HV in the traffic stream, is one method to consider the impact of HVs in roundabout entry capacity estimation. Compared to the passenger cars only cases, entry capacity would be decreased with increasing the HV percentage. However, in Highway Capacity Manual $(\mathrm{HCM}) 6^{\text {th }}$ edition $^{1)}$ and Japan Roundabout Manual (JRM) ${ }^{2)}$, PCE for HVs at entry of roundabouts is assumed as a constant value of 2.0, which cannot represent situations under various vehicle compositions and different geometric elements. In the empirical analysis, it is very difficult to get sufficient data of HV samples in Japan where the number of roundabouts is still limited. Therefore, this study proposes an alternative method to supplement the missing gap parameters for vehicle compositions.

Furthermore, this study investigates the influence of vehicle types and geometric elements on roundabout entry capacity by using traffic simulator VISSIM 10.00 (VISSIM) ${ }^{3)}$ and estimates the PCE ranges for HVs depending on roundabout geometric elements. Thus, the objective of this paper is to 
estimate PCE ranges for HVs considering various geometric elements of roundabouts.

\section{LITERATURE REVIEW}

There are two methods to consider the impact of HVs on roundabout entry capacity; one is to adjust headway parameters of HVs in the entry capacity equation based on gap acceptance theory and the other is to adjust entry capacity directly by using PCEs for HVs.

Lee $^{4)}$ obtained PCE based on empirical data at roundabouts in the United States. It is anticipated that the PCE value is different depending on the maximum size of $\mathrm{HV}$ and driving maneuver.

Goto, et al. ${ }^{5)}$ estimated PCEs for HVs based on empirical observations in Japan as well as simulated data. They concluded that PCE values range between 1.4 to 3.0 on the entry approach and 1.3 to 1.5 on the circulatory roadway. However, the layout is limited to only one standard 4-leg roundabout, thus the impact of roundabout geometry was not considered.

With regard to the entry capacity considering different geometric elements, Kimber ${ }^{6)}$ determined six geometric factors that have significant influence on the entry capacity and used them to propose a function named Kimber's capacity model to estimate roundabout entry capacity.

Kanbe, et al. ${ }^{7)}$ investigated the impact of geometric elements based on Kimber's geometric parameters using the data collected at four roundabouts in Japan. In their empirical models, no HVs were analyzed in the entry and circulating flows.

Zhao, et al. ${ }^{8)}$ investigated both the influence of vehicle types and geometric elements on entry capacity. It was concluded that the driving maneuver of $\mathrm{HV}$ is significantly affected by roundabout geometric design. However, due to the limitation of empirical data, PCEs could not be estimated.

The previous studies only considered either impact of HV or geometric design on roundabout capacity, and there is no research focusing on both of them on capacity. Therefore, this paper proposes a method to supplement the missing gap data for HVs, then PCE ranges based on roundabout geometric elements are estimated by using the supplemented data.

\section{METHODOLOGY}

\section{(1) Geometric elements and operational variables}

This paper defines six geometric factors which may have influence on entry capacity. As shown in Fig. 1, they are: Entry width $W_{e}(\mathrm{~m})$, the width of the entry approach from splitter island to the roadside

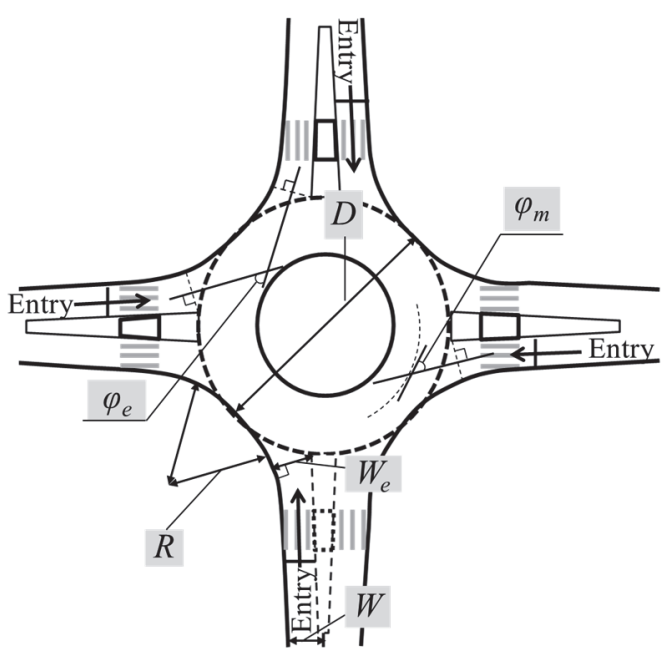

Fig.1 Roundabout geometric elements.

Table 1 Study sites and observed period.

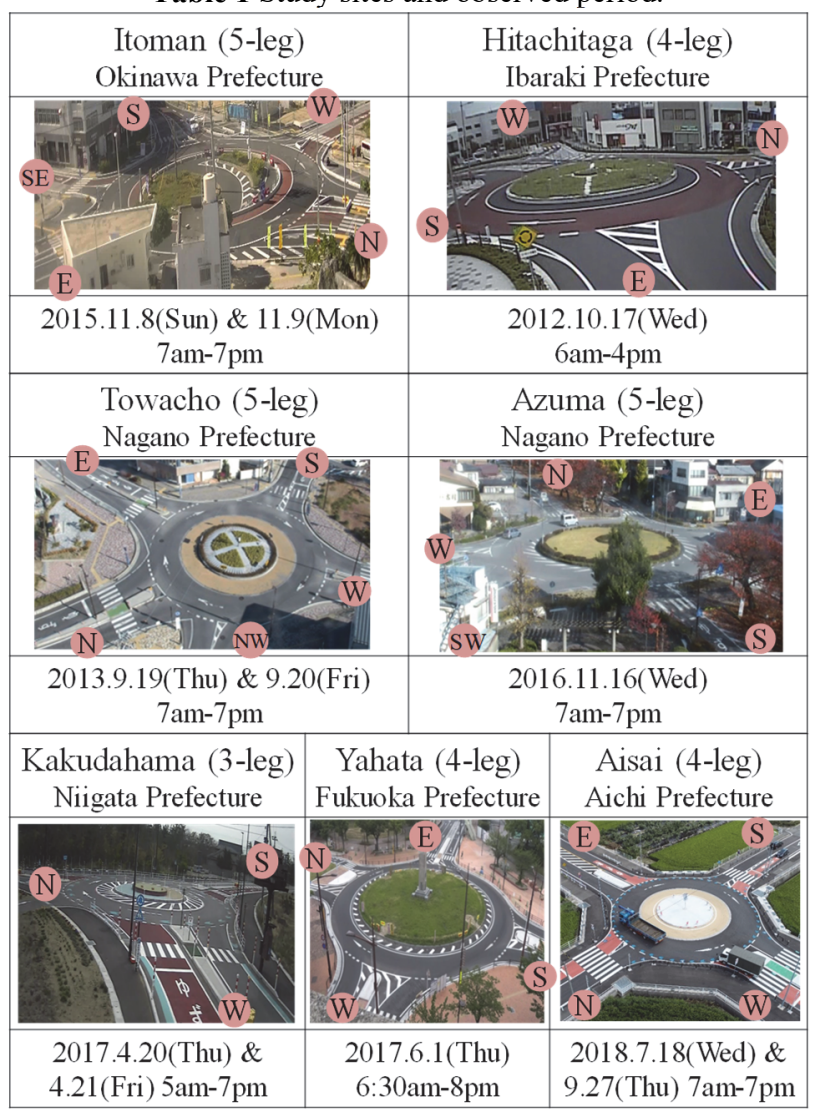

curb, which is measured from the summit corner of splitter island then vertical to the curb; Approach half width $W(\mathrm{~m})$, the width of lane of entry approach; Inscribed circle diameter $D(\mathrm{~m})$; Entry radius $R(\mathrm{~m})$, the radius of the curve of entry approach; Entry angle $\varphi_{e}(\mathrm{deg})$, the angle between entering direction and next downstream exiting direction, which is the angle between lines vertical to the entry width of entry approach and vertical to exit width of the next downstream approach; and Merging angle $\varphi_{m}(\mathrm{deg})$, the angle between vertical line of the entry width and the tangent line of the center circle of the circulating 
roadway. First five of them are based on the geometric elements proposed by Kimber ${ }^{6)}$ and the last one of them is proposed by Kanbe, et al. ${ }^{7)}$. The impact of these parameters are investigated in this study by using empirical data. All of the geometric elements are measured using splitter islands of entry approaches and roadside curbs as references. If there is no splitter island, then the distance is measured from the summit corner of the zebra marking of "splitter island" and vertical to the roadside curb.

In order to analyze the relationship between geometric elements and gap parameters, video surveys were conducted on sunny days at seven roundabouts (RABs) in Japan. All of them are single lane RABs under yield-control. The photographs and observed periods are summarized in Table 1. The gap data was observed from videos by using the image processing system TrafficAnalyzer ${ }^{9}$. Since some of the videos were recorded right after the roundabouts were newly in operation, in order to represent this impact, a dummy variable $d_{o p}$ is defined as 1 for the first three months and 0 otherwise. A dummy variable $d_{s p}$ is assumed 1 for the approach constructed with splitter island and 0 for otherwise.

The detailed geometric elements and dummy variables measured in each site for 29 approaches in total are summarized in Table 2, where the range of each geometric element varies widely.

\section{(2) Gap parameters}

The entry capacity is the maximum number of vehicles that are expected to enter roundabout from one approach during a certain period. The $\mathrm{JRM}^{2)}$ estimates the entry capacity by Equation (1) which is based on the gap acceptance theory by defining three gap parameters in circulating and entry flows.

$$
\begin{gathered}
c_{i}=\frac{3600}{t_{f}}\left(1-\tau \frac{Q_{r}}{3600}\right) \\
\times \exp \left[-\frac{Q_{r}}{3600}\left(t_{c}-\frac{t_{f}}{2}-\tau\right)\right]
\end{gathered}
$$

Where, $c_{i}$. entry capacity of entry $i$ in the unit of $\mathrm{pcu} / \mathrm{h}, Q_{r}$ : circulating flow at the entry $i$ in the unit of $\mathrm{pcu} / \mathrm{h}$. The three gap parameters are: $t_{c}$ : critical

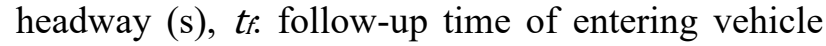
(s), $\tau$. minimum headway of circulating flow (s).

The definitions of three gap parameters and their measurement methods are illustrated in Fig. 2 and $\mathbf{3 .}$

\section{a) Critical headway $t_{c}$}

Critical headway is defined as the minimum acceptable headway between two circulating vehicles where the gap is judged by entering vehicle to accept or reject. In the case of $t_{c}$, only the gaps under $10 \mathrm{~s}$ were collected. Raff's method ${ }^{10)}$ is utilized to estimate the value of $t_{c}$ for each approach, which defined $t_{c}$ is the intersecting point of the cumulative distributions of accepted and rejected gaps.

\begin{tabular}{|c|c|c|c|c|c|c|c|c|c|}
\hline \multirow{3}{*}{ RAB } & \multirow{3}{*}{ Appro. } & \multicolumn{6}{|c|}{ Geometry elements } & \multirow{2}{*}{\multicolumn{2}{|c|}{$\begin{array}{c}\text { Dummy } \\
\text { variables }\end{array}$}} \\
\hline & & \multirow{2}{*}{$\begin{array}{l}W_{e} \\
(\mathrm{~m})\end{array}$} & \multirow{2}{*}{$\begin{array}{c}W \\
(\mathrm{~m})\end{array}$} & \multirow{2}{*}{$\begin{array}{c}D \\
(\mathrm{~m})\end{array}$} & \multirow{2}{*}{$\begin{array}{c}R \\
(\mathrm{~m}) \\
\end{array}$} & \multirow{2}{*}{\begin{tabular}{|c|}
$\varphi_{e}$ \\
$(\mathrm{deg})$
\end{tabular}} & \multirow{2}{*}{$\frac{\varphi_{m}}{(\mathrm{deg})}$} & & \\
\hline & & & & & & & & $d_{o p}$ & $d_{s p}$ \\
\hline \multirow{5}{*}{ Itoman } & $\mathrm{N}$ & 3.12 & 3.15 & 39.0 & 9.36 & 15.0 & 38.0 & 1 & 1 \\
\hline & $E$ & 2.94 & 4.00 & 39.0 & 9.36 & 74.0 & 36.0 & 1 & 1 \\
\hline & SE & 3.21 & 3.00 & 39.0 & 6.78 & 53.0 & 44.0 & 1 & 0 \\
\hline & $\mathrm{S}$ & 2.94 & 2.95 & 39.0 & 9.36 & 45.0 & 35.0 & 1 & 1 \\
\hline & $\mathrm{W}$ & 2.94 & 3.50 & 39.0 & 15.4 & 54.0 & 27.0 & 1 & 1 \\
\hline \multirow{3}{*}{$\begin{array}{l}\text { Hitachi } \\
\text { taga }\end{array}$} & $\mathrm{E}$ & 4.65 & 4.15 & 28.0 & 11.9 & 32.0 & 30.0 & 0 & 0 \\
\hline & $\mathrm{W}$ & 3.48 & 3.16 & 28.0 & 10.5 & 22.0 & 42.0 & 0 & 0 \\
\hline & $\mathrm{N}$ & 5.26 & 5.53 & 28.0 & 10.4 & 26.0 & 22.0 & 0 & 0 \\
\hline \multirow{5}{*}{$\begin{array}{l}\text { Towa } \\
\text { cho }\end{array}$} & $\mathrm{N}$ & 6.78 & 4.48 & 30.0 & 13.0 & 58.0 & 21.0 & 0 & 1 \\
\hline & NW & 5.45 & 3.25 & 30.0 & 16.0 & 94.0 & 38.0 & 0 & 0 \\
\hline & $\mathrm{W}$ & 4.95 & 3.20 & 30.0 & 13.0 & 47.0 & 45.0 & 0 & 1 \\
\hline & $\mathrm{S}$ & 4.17 & 4.64 & 30.0 & 13.0 & 56.0 & 32.0 & 0 & 0 \\
\hline & $\mathrm{E}$ & 4.60 & 3.24 & 30.0 & 13.0 & 51.0 & 43.0 & 0 & 1 \\
\hline \multirow{5}{*}{ Azuma } & $\mathrm{N}$ & 6.02 & 3.56 & 39.0 & 15.6 & 68.0 & 48.0 & 0 & 1 \\
\hline & E & 4.74 & 4.34 & 39.0 & 10.3 & 65.0 & 41.0 & 0 & 0 \\
\hline & $\mathrm{S}$ & 5.79 & 3.59 & 39.0 & 7.76 & 77.0 & 51.0 & 0 & 1 \\
\hline & SW & 7.73 & 3.84 & 39.0 & 5.35 & 63.0 & 48.0 & 0 & 0 \\
\hline & $\mathrm{W}$ & 4.77 & 4.40 & 39.0 & 7.84 & 50.0 & 36.0 & 0 & 0 \\
\hline \multirow{3}{*}{$\begin{array}{c}\text { Kakuda } \\
\text { hama }\end{array}$} & $\mathrm{N}$ & 5.68 & 4.10 & 30.0 & 29.2 & 19.0 & 38.0 & 0 & 1 \\
\hline & $\mathrm{S}$ & 6.23 & 4.10 & 30.0 & 29.7 & 11.0 & 30.0 & 0 & 1 \\
\hline & W & 6.12 & 4.25 & 30.0 & 30.0 & 37.0 & 39.0 & 0 & 1 \\
\hline \multirow{4}{*}{ Yahata } & $\mathrm{E}$ & 3.83 & 4.01 & 44.0 & 10.3 & 35.5 & 56.7 & 1 & 1 \\
\hline & $\mathrm{S}$ & 3.77 & 3.52 & 44.0 & 10.3 & 62.6 & 56.1 & 1 & 1 \\
\hline & $\mathrm{W}$ & 3.75 & 4.04 & 44.0 & 10.3 & 65.4 & 53.2 & 1 & 1 \\
\hline & $\mathrm{N}$ & 3.76 & 3.77 & 44.0 & 10.3 & 71.4 & 62.9 & 1 & 1 \\
\hline \multirow{4}{*}{ Aisai } & $\mathrm{W}$ & 4.17 & 4.02 & 27.0 & 6.0 & 54.0 & 49.0 & 1 & 1 \\
\hline & $\mathrm{N}$ & 3.75 & 3.50 & 27.0 & 9.0 & 42.0 & 34.0 & 1 & 0 \\
\hline & $\mathrm{E}$ & 4.54 & 4.41 & 27.0 & 6.0 & 51.0 & 52.0 & 1 & 1 \\
\hline & $\mathrm{S}$ & 3.75 & 3.50 & 27.0 & 9.0 & 38.0 & 34.0 & 1 & 0 \\
\hline
\end{tabular}

Table 2 Geometric elements and dummy variables.

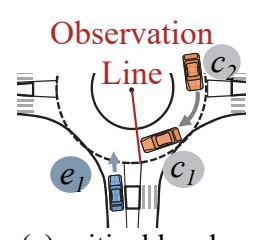

(a) critical headway $t_{c}$

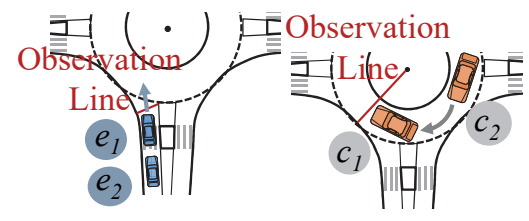

(b) follow-up time $t_{f}$

ig. 2 Gap parameters. (c) minimum headway $\tau$

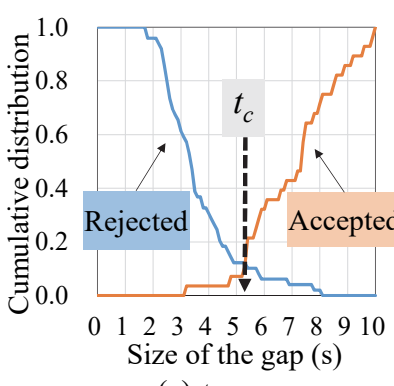

(a) $t_{c}$

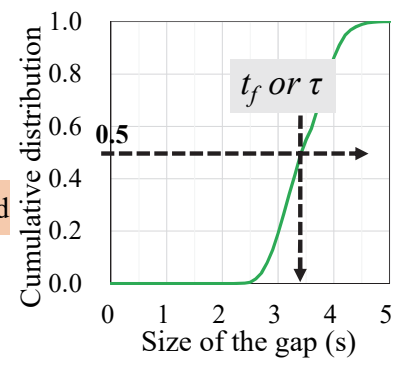

(b) $t_{f}$ and $\tau$
Fig.3 Measurement methods.

\section{b) Follow-up time $t_{f}$ and minimum headway on circulatory roadway $\tau$}

Follow-up time $t_{f}$ and minimum headway on circulatory roadway $\tau$ are headways between leading vehicle and follow-up vehicle of entry approach and circulatory roadway, respectively. Only the headways below $5 \mathrm{~s}$ were collected and then the 50 percentile value of the cumulative distribution is defined as its crirical value for $t_{f}$ and $\tau$, respectively. 


\section{(3) Vehicle compositions}

According to the Explanation and Description of Road Structure Ordinance ${ }^{11)}$, vehicle with a length of over $6 \mathrm{~m}$ is defined as HV. Considering the positions of $\mathrm{HV}$ in the gap acceptance behavior, there are eight compositions for $t_{c}$, four compositions for $t_{f}$ and four compositions for $\tau$, as summarized in Table 3 where $H$ and $P$ represent for $\mathrm{HV}$ and passenger car (PC), respectively. $e_{1}, e_{2}, c_{1}$ and $c_{2}$ represent leading entering vehicle, following entering vehicle, leading circulating vehicle and following circulating vehicle, respectively.

\section{(4) Sample size}

The obtained gap parameters after processing the videos are illustrated in Table $\mathbf{4}$ and the cell colors represent for reliability of gaps according to sample size $n$. Green, yellow, red and white represent the number of observed gaps which exceed 30 , from 10 to 30 , from 5 to 10 and less than 5 , respectively. $n$ of green colored cells can be regarded as reliable enough and those of yellow colored cells are considerably reliable. For the relatively limited $n$ of the red colored cells, the distributions of gap parameters are not smooth, thus the processed data are considered less realistic. However, for the infrequent cases including HVs, the data are still used for calculation hereinafter. Regarding the $n$ in white colored cells, the obtained values are considered not reliable enough for analysis and not used for modeling. Thus, for PC compositions, most of the $n$ exceed 30 highlighted in green color, which are considered sufficient for data analysis. However, $n$ of compositions including one $\mathrm{HV}$ is quite limited, and there is no observed data for compositions including more than and equal to two HVs. In order to analyze the impact of geometry on all the cases, thus, a supplementation method is proposed to predict the gap parameters for all vehicle compositions.

\section{(5) Alternative method for vehicle compositions \\ a) Estimation of Multiplier $r$}

Since the empirical data is insufficient, a supplementation and adjustment calculation procedure is carried out for predicting the gaps of all compositions. The six roundabouts excluding Aisai$\mathrm{RAB}$ were used for evaluating the multiplier ratio between $\mathrm{HV}$ and PC. Aisai-RAB is selected for the validation of the multiplier because it contains relatively high heavy vehicle percentage (about 20\%) in the flow and have the empirical data for most of the compositions among the study sites.

Due to HV's large size and lower driving speed, the compositions which include HV would significantly affect the gap acceptance. In order to predict the gap parameters for all the compositions,
Table 3 Vehicle compositions.

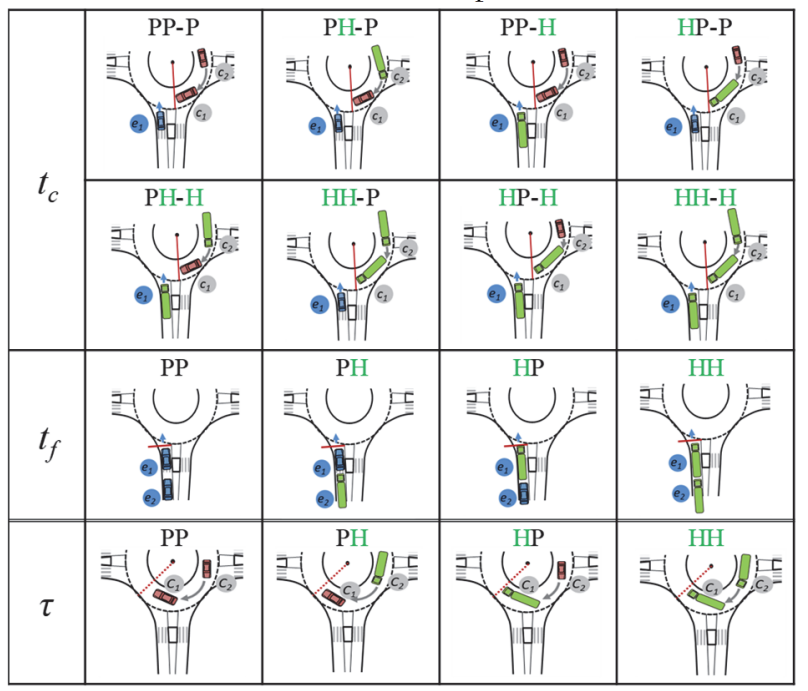

Table 4 Observed gap parameters and their sample size. \begin{tabular}{l|l|l|l|l|l|} 
Legend of sample size $30<=n$ & $10<=n<30$ & $5<=n<10$ & "-" $n<5$ unused \\
\hline
\end{tabular}

\begin{tabular}{|c|c|c|c|c|c|c|c|c|c|c|c|}
\hline \multirow{2}{*}{ RAB } & \multirow{2}{*}{ Appro. } & \multicolumn{4}{|c|}{$t_{c}$} & \multicolumn{3}{|c|}{$t_{f}$} & \multicolumn{3}{|c|}{$\tau$} \\
\hline & & PP-P & PH-P & PP-H & HP-P & PP & $\mathrm{PH}$ & HP & PP & PH & HP \\
\hline \multirow{5}{*}{ Itoman } & $\mathrm{N}$ & 5.50 & - & 6.80 & - & 2.78 & 3.17 & 4.15 & 2.75 & 3.45 & 4.00 \\
\hline & E & 5.00 & 5.30 & 5.80 & - & 3.07 & 3.65 & 4.80 & 2.65 & 3.35 & 3.50 \\
\hline & SE & 5.10 & - & 5.70 & - & 3.60 & - & - & 2.70 & 3.90 & 3.58 \\
\hline & $\mathrm{S}$ & 6.00 & - & - & - & 3.23 & 3.50 & 4.02 & 2.75 & 3.12 & 3.92 \\
\hline & W & 4.60 & - & 6.10 & - & 3.29 & - & - & 2.60 & 3.10 & 4.02 \\
\hline \multirow{3}{*}{$\begin{array}{c}\text { Hitachi } \\
\text { taga }\end{array}$} & E & 5.30 & - & - & 6.30 & 3.30 & 3.25 & 4.00 & 2.85 & 3.65 & 3.70 \\
\hline & W & 4.50 & 5.10 & 5.50 & 5.60 & 3.15 & 2.91 & 3.60 & 2.90 & 3.30 & 4.17 \\
\hline & $\mathrm{N}$ & 4.50 & 5.30 & 5.50 & - & 3.00 & 3.35 & 3.90 & 2.85 & 2.95 & 3.35 \\
\hline \multirow{5}{*}{$\begin{array}{c}\text { Towa } \\
\text { cho }\end{array}$} & $\mathrm{N}$ & 5.40 & 5.30 & - & - & 2.60 & - & 2.90 & 2.68 & 3.15 & 2.97 \\
\hline & NW & 4.60 & 7.00 & 5.70 & - & - & - & - & 2.77 & 2.75 & 3.03 \\
\hline & W & 4.70 & - & - & - & 2.80 & 3.73 & 3.48 & 2.63 & 2.67 & 3.19 \\
\hline & $\mathrm{S}$ & 4.80 & - & - & - & 2.90 & 3.85 & 4.00 & 2.65 & 2.70 & 3.50 \\
\hline & $E$ & 5.00 & - & - & - & 2.65 & 3.85 & 3.40 & 2.68 & 3.05 & 3.30 \\
\hline \multirow{5}{*}{ Azuma } & $\mathrm{N}$ & 4.90 & - & - & - & 2.81 & - & 3.35 & 2.70 & 3.25 & 3.18 \\
\hline & E & 5.00 & - & - & - & 2.93 & 2.35 & 3.65 & 2.63 & 3.10 & 3.45 \\
\hline & $S$ & 4.90 & - & - & - & 2.78 & 3.35 & 3.88 & 2.65 & 2.42 & 3.02 \\
\hline & SW & 4.80 & - & - & - & 2.72 & 2.95 & 3.90 & 2.65 & 2.35 & 2.95 \\
\hline & W & 4.30 & - & - & - & 2.85 & - & - & 2.53 & 2.85 & 3.10 \\
\hline \multirow{3}{*}{$\begin{array}{c}\text { Kakuda } \\
\text { hama }\end{array}$} & $\mathrm{N}$ & 5.46 & - & - & - & 3.00 & 3.20 & 3.65 & 2.97 & 2.60 & 3.18 \\
\hline & $\mathrm{S}$ & 5.46 & - & - & - & 2.62 & - & 3.25 & 2.98 & 2.95 & 3.23 \\
\hline & $\mathrm{W}$ & 4.72 & - & - & - & 2.65 & 3.58 & 3.75 & 2.50 & 2.95 & 3.35 \\
\hline \multirow{4}{*}{ Yahata } & E & 4.86 & - & - & - & 2.47 & 3.25 & 3.05 & 2.60 & 3.35 & 3.38 \\
\hline & $\mathrm{S}$ & 4.55 & - & - & - & 2.65 & - & - & 2.63 & - & 3.68 \\
\hline & $\mathrm{W}$ & 4.10 & - & - & - & 2.66 & - & 3.82 & 2.40 & 2.48 & 3.95 \\
\hline & $\mathrm{N}$ & 4.26 & - & 5.73 & - & 2.57 & - & - & 2.48 & 3.95 & 3.75 \\
\hline \multirow{4}{*}{ Aisai } & W & 5.20 & - & - & - & 2.90 & 3.50 & 4.10 & 2.70 & 2.80 & 3.50 \\
\hline & $\mathrm{N}$ & 6.50 & - & - & - & 3.20 & 3.80 & 4.20 & 2.80 & 2.90 & 3.80 \\
\hline & E & 6.00 & - & - & - & 3.10 & 3.40 & 4.00 & 2.90 & - & 4.10 \\
\hline & $\mathrm{S}$ & 5.30 & 6.00 & - & - & 3.60 & - & 4.20 & 2.90 & 3.40 & 3.80 \\
\hline
\end{tabular}

the influence of HVs' driving behavior should first be considered. The ratios between each composition including HVs and the composition including PCs only are calculated. Then mean values of all the available ratios for each composition are estimated as multiplier $r$, which represents the HV impact of this case divided by PC case.

Therefore, $r$ for the case of passenger car only is 1.0, and the $r$ for the compositions including one HV is estimated as the calculated mean ratio based on the empirical gaps. As for the compositions including more than and equal to two HVs, the $r$ is estimated considering different features at $c_{1}, c_{2}, e_{1}$ and $e_{2}$, respectively, for different positions of $\mathrm{HV}$ in the 
gaps. Then the HV impacts are combined together for calculating the $r$ for all the vehicle compositions as shown in Table 5.

Finally, the vehicle compositions which have insufficient samples were supplemented by multiplying the estimated $r$ to PC cases for each approach, whereas the existing observed data remain their values in the database.

\section{b) Validation of Multiplier $r$}

The applicability of $r$ at any other roundabout should be validated. Therefore, the data of Aisai$\mathrm{RAB}$ with high heavy vehicle percentage is selected for validation.

By applying $r$ to gaps of PC compositions at Aisai$\mathrm{RAB}$, the calculated gaps of compositions contain HVs are compared with the observed ones. Mean Absolute Percentage Error (MAPE) is used for evaluating the difference between calculated and observed values by Equation (2). All of the MAPEs of available compositions are less than $10 \%$, which indicate that these estimated $r$ are considered as representative values for the $\mathrm{HV}$ compositions.

$$
\begin{gathered}
\text { MAPE }= \\
\frac{\sum_{n} \mid \frac{\text { estimated gap - observed gap }}{\text { observed gap }}}{n}
\end{gathered}
$$

\section{c) Adjustment for geometric impacts}

By applying the estimated $r$, the gaps which have insufficient samples were supplemented. However, for the compositions which contain more than and equal to two HVs may depend on the PC data too much since there is no empirical data to refer to. Furthermore, $r$ cannot reflect the impact of geometric design over other vehicle compositions. Therefore, an adjustment procedure considering geometric elements is applied to eliminate this limitation. Thus, the compositions with only one $\mathrm{HV}$ can be supplemented by estimated multiplier $r$, and for the compositions with more than and equal to two HVs, Equations (3a) $-(3 c)$ are proposed for calculation by fully using the observed gaps including HVs. The empirical data of compositions with only one HV can also be utilized along with the empirical data of PC only cases, that can reflect the geometric impacts on $\mathrm{HV}$, not only on PC.

$$
t_{c_{i}}=\left[\begin{array}{c}
\frac{r\left(t_{c_{i}}\right)}{r\left(t_{c_{H P}-P}\right)} \times t_{c_{H P}-P} \times d_{c 1} \\
+\frac{r\left(t_{c_{i}}\right)}{r\left(t_{c_{P H}-P}\right)} \times t_{c_{P H}-P} \times d_{c 2} \\
+\frac{r\left(t_{c_{i}}\right)}{r\left(t_{c_{P P}-H}\right)} \times t_{c_{P P}-H} \times d_{e 1}
\end{array}\right]
$$

Table 5 Estimated multiplier $r$.

\begin{tabular}{|c|c|c|c|c|}
\hline \multirow{4}{*}{$t_{c}$} & PP-P / PP-P & PH-P / PP-P & PP-H / PP-P & HP-P / PP-P \\
\cline { 2 - 5 } & 1.0 & $\begin{array}{c}1.1 \\
(+0.1)\end{array}$ & $\begin{array}{c}1.2 \\
(+0.2)\end{array}$ & $\begin{array}{c}1.3 \\
(+0.3)\end{array}$ \\
\cline { 2 - 5 } & $\mathrm{PH}-\mathrm{H} / \mathrm{PP}-\mathrm{P}$ & $\mathrm{HH}-\mathrm{P} / \mathrm{PP}-\mathrm{P}$ & $\mathrm{HP}-\mathrm{H} / \mathrm{PP}-\mathrm{P}$ & $\mathrm{HH}-\mathrm{H} / \mathrm{PP}-\mathrm{P}$ \\
\cline { 2 - 5 } & 1.3 & $\begin{array}{c}1.4 \\
(+0.1+0.2)\end{array}$ & $\begin{array}{c}1.5 \\
(+0.3+0.2)\end{array}$ & $\begin{array}{c}1.6 \\
(+0.3+0.1+0.2)\end{array}$ \\
\hline \hline \multirow{4}{*}{$t f$} & $\mathrm{PP} / \mathrm{PP}$ & $\mathrm{PH} / \mathrm{PP}$ & $\mathrm{HP} / \mathrm{PP}$ & $\mathrm{HH} / \mathrm{PP}$ \\
\cline { 2 - 5 } & 1.0 & $\begin{array}{c}1.2 \\
(+0.2)\end{array}$ & $\begin{array}{c}1.3 \\
(+0.3)\end{array}$ & $\begin{array}{c}1.5 \\
(+0.3+0.2)\end{array}$ \\
\hline \hline \multirow{4}{*}{$\tau$} & $\mathrm{PP} / \mathrm{PP}$ & $\mathrm{PH} / \mathrm{PP}$ & $\mathrm{HP} / \mathrm{PP}$ & $\mathrm{HH} / \mathrm{PP}$ \\
\cline { 2 - 5 } & 1.0 & $\begin{array}{c}1.1 \\
(+0.1)\end{array}$ & $\begin{array}{c}1.3 \\
(+0.3)\end{array}$ & $\begin{array}{c}1.4 \\
(+0.3+0.1)\end{array}$ \\
\hline
\end{tabular}

$$
\begin{gathered}
t_{f_{-} j}=\left[\frac{r\left(t_{f_{-} j}\right)}{r\left(t_{f_{-} H P}\right)} \times t_{f_{-} H P} \times d_{e 1}\right. \\
\left.\quad+\frac{r\left(t_{f_{-} j}\right)}{r\left(t_{f_{-} P H}\right)} \times t_{f_{-} P H} \times d_{e 2}\right] \\
\tau_{\tau_{k} k}=\left[\frac{r\left(d_{e 1}+d_{e 2}\right)}{r\left(\tau_{-}\right)} \times \tau_{-H P} \times d_{c 1}\right. \\
\left.+\frac{r\left(\tau_{-}\right)}{r\left(\tau_{-P H}\right)} \times \tau_{-P H} \times d_{c 2}\right] \\
/\left(d_{c 1}+d_{c 2}\right)
\end{gathered}
$$

Where, $t_{c_{-},}, t_{f_{-} j}$ and $\tau_{-k}$ represent the gaps after supplement and adjustment procedure. $i, j$ and $k$ represent vehicle compositions; $i$ represents $t_{c}$ vehicle combination of $d_{c 1} d_{c 2}-d_{e 1}, j$ and $k$ represent vehicle combination of $d_{e 1} d_{e 2}$ and $d_{c 1} d_{c 2}$ for $t_{f}$ and $\tau$, respectively. $r$ represents the estimated multiplier $r$ for each composition. $d_{c 1}, d_{c 2}, d_{e 1}$ and $d_{e 2}$ are dummy variables for $\mathrm{HV}$, if $c_{1}, c_{2}, e_{1}$ or $e_{2}$ is $H$ then $d_{c 1}, d_{c 2}, d_{e 1}$ and $d_{e 2}$ $=1$, respectively, otherwise $=0$.

For example of $t_{c}$, the most complex composition including three HVs presents $t_{c_{-} H H-H}=\left(1.6 / 1.1 * t_{c_{-} P H-P}\right.$ $\left.+1.6 / 1.2 * t_{c_{-} P P-H}+1.6 / 1.3 * t_{C_{-} H P-P}\right) / 3$.

Therefore, the multiplier $r$ reflecting the impact of $\mathrm{HV}$ and the adjustment procedure considering geometric impact are used for supplement the insufficient data.

\section{MODELING GAP PARAMETERS}

As the database has been successfully supplemented, the relationship between gaps and geometric elements are compared by each vehicle composition. As shown in Fig.4, for $t_{c}$, PP-P, PP-H, $\mathrm{HH}-\mathrm{P}$ and $\mathrm{HH}-\mathrm{H}$ are selected as typical compositions of passenger car only case and which including one, two and three HVs in the gap respectively, for comparing with the inscribed circle diameter. These compositions have a decreasing trend of $t_{c}$ with increase in diameter. That reveals a significant influence of size of RAB on gap acceptance behavior for both PC and HV. In Fig.5, $W_{e}$ is related to HV compositions of $\tau$, however it is not significant for PP 


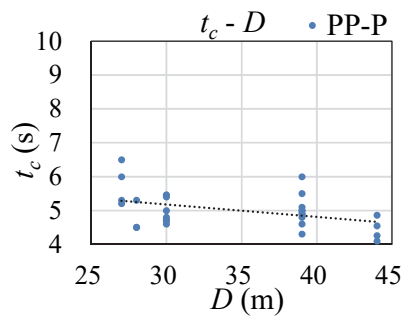

(a) PP-P

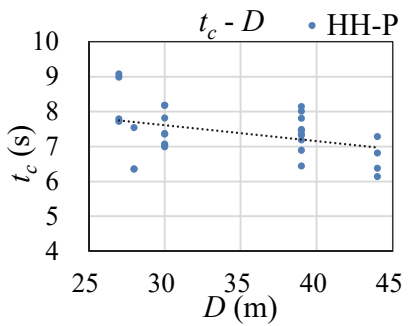

(c) HH-P

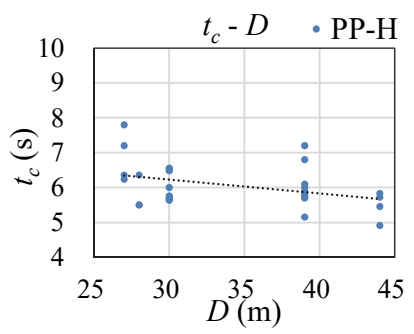

(b) PP-H

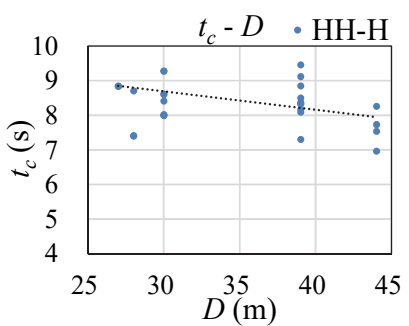

(d) $\mathrm{HH}-\mathrm{H}$
Fig.4 Relationship between $t_{c}$ and $D$.

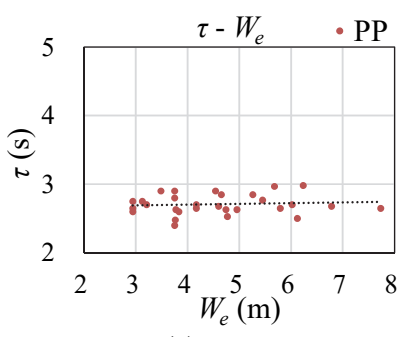

(a) $\mathrm{PP}$

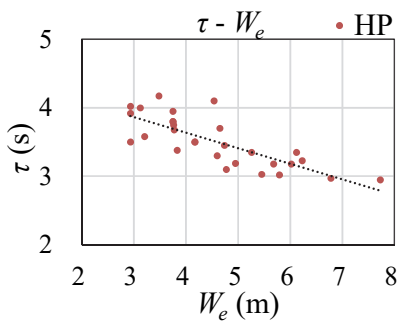

(c) HP

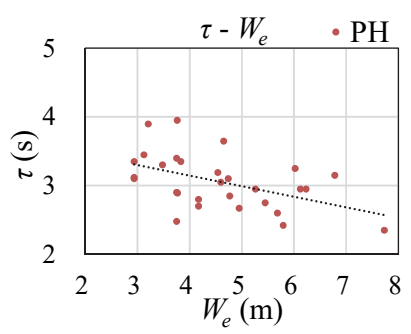

(b) $\mathrm{PH}$

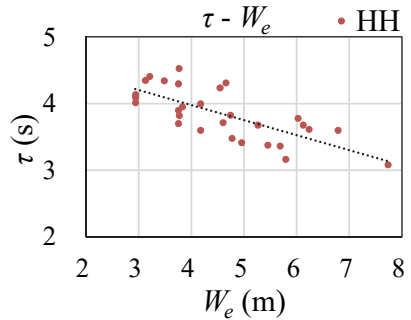

(d) $\mathrm{HH}$
Fig.5 Relationship between $\tau$ and $W e$.

case. It is considered that this geometric element only limits driving behavior of $\mathrm{HV}$ but not for PC. Considering various compositions of gap parameters are compared with geometric elements, as well as the limitation of sample size, relationships such as exponential curves are hard to be observed. Therefore, linear regression is adopted for evaluating the influence of geometric elements on gap parameters of each vehicle compositions.

The models for three gap parameters are shown in Table 6. Two geometric elements $D$ and $W_{e}$, and one operational dummy $d_{s p}$ significantly affect gap parameters. All the three gap parameters are influenced by $D$, which reveals that the size of roundabout generally determines the entry capacity. Since the geometry of circulatory roadway is affected by $D$ directly, with larger $D$, the trajectory of vehicle on the circulatory roadway approaches to straight line. For this reason, in $t_{c}$, entering vehicle could get
Table 6 Estimation results of models for $t_{c}, t_{f}$ and $\tau$. (a) Models for $t_{c}$

\begin{tabular}{|c|c|c|c|c|}
\hline \multirow[b]{2}{*}{$t_{c}$} & PP-P & PH-P & PP-H & HP-P \\
\hline & $\begin{array}{c}\text { Coef. } \\
\text { (t-value) }\end{array}$ & $\begin{array}{c}\text { Coef. } \\
\text { (t-value) }\end{array}$ & $\begin{array}{c}\text { Coef. } \\
\text { (t-value) }\end{array}$ & $\begin{array}{c}\text { Coef. } \\
\text { (t-value) }\end{array}$ \\
\hline Intercept & $\begin{array}{c}6.27 \\
(11.5 * *)\end{array}$ & $\begin{array}{c}7.46 \\
(10.4 * *)\end{array}$ & $\begin{array}{c}7.41 \\
(11.7 * *)\end{array}$ & $\begin{array}{c}7.94 \\
\left(10.9^{* *}\right)\end{array}$ \\
\hline$D$ & $\begin{array}{l}-0.0365 \\
\left(-2.34^{*}\right) \\
\end{array}$ & $\begin{array}{l}-0.0431 \\
(-2.11 *) \\
\end{array}$ & $\begin{array}{l}-0.0395 \\
(-2.18 *) \\
\end{array}$ & $\begin{array}{l}-0.0424 \\
\left(-2.03^{*}\right) \\
\end{array}$ \\
\hline $\mathrm{R}^{2}$ & 0.169 & 0.142 & 0.150 & 0.133 \\
\hline $\mathrm{N}$ & 29 & 29 & 29 & 29 \\
\hline \multirow[b]{2}{*}{$t_{c}$} & PH-H & HH-P & HP-H & $\mathrm{HH}-\mathrm{H}$ \\
\hline & $\begin{array}{c}\text { Coef. } \\
\text { (t-value) }\end{array}$ & $\begin{array}{c}\text { Coef. } \\
\text { (t-value) }\end{array}$ & $\begin{array}{c}\text { Coef. } \\
\text { (t-value) }\end{array}$ & $\begin{array}{c}\text { Coef. } \\
\text { (t-value) }\end{array}$ \\
\hline Intercept & $\begin{array}{c}8.67 \\
\left(11.6^{* *}\right)\end{array}$ & $\begin{array}{c}9.24 \\
(11.2 * *)\end{array}$ & $\begin{array}{c}9.22 \\
(11.5 * *)\end{array}$ & $\begin{array}{c}10.48 \\
\left(11.6^{* *}\right)\end{array}$ \\
\hline$D$ & $\begin{array}{l}-0.0482 \\
\left(-2.26^{*}\right)\end{array}$ & $\begin{array}{l}-0.0514 \\
\left(-2.18^{*}\right)\end{array}$ & $\begin{array}{l}-0.0492 \\
(-2.14 *) \\
\end{array}$ & $\begin{array}{l}-0.0575 \\
(-2.22 *)\end{array}$ \\
\hline $\mathrm{R}^{2}$ & 0.159 & 0.150 & 0.145 & 0.155 \\
\hline $\mathrm{N}$ & 29 & 29 & 29 & 29 \\
\hline
\end{tabular}

(b) Models for $t_{f}$

\begin{tabular}{|c|c|c|c|c|}
\hline \multirow[b]{2}{*}{$t_{f}$} & $\mathrm{PP}$ & $\mathrm{PH}$ & HP & $\mathrm{HH}$ \\
\hline & $\begin{array}{c}\text { Coef. } \\
\text { (t-value) }\end{array}$ & $\begin{array}{c}\text { Coef. } \\
\text { (t-value) }\end{array}$ & $\begin{array}{c}\text { Coef. } \\
\text { (t-value) }\end{array}$ & $\begin{array}{c}\text { Coef. } \\
\text { (t-value) }\end{array}$ \\
\hline Intercept & $\begin{array}{c}4.17 \\
\left(13.0^{* *}\right)\end{array}$ & $\begin{array}{c}3.96 \\
(13.9 * *)\end{array}$ & $\begin{array}{c}4.60 \\
\left(16.5^{* *}\right)\end{array}$ & $\begin{array}{c}5.08 \\
\left(17.8^{* *}\right)\end{array}$ \\
\hline$W_{e}$ & $\begin{array}{c}-0.130 \\
(-3.78 * *)\end{array}$ & $\begin{array}{c}-0.120 \\
(-2.00 *)\end{array}$ & $\begin{array}{c}-0.177 \\
(-3.01 * *)\end{array}$ & $\begin{array}{c}-0.172 \\
\left(-2.85^{* *}\right)\end{array}$ \\
\hline$D$ & $\begin{array}{l}-0.0152 \\
(-2.09 *)\end{array}$ & - & - & - \\
\hline$d_{s p}$ & $\begin{array}{c}-0.226 \\
\left(-2.56^{*}\right) \\
\end{array}$ & - & - & - \\
\hline $\mathrm{R}^{2}$ & 0.509 & 0.129 & 0.251 & 0.232 \\
\hline $\mathrm{N}$ & 29 & 29 & 29 & 29 \\
\hline
\end{tabular}

(c) Models for $\tau$

\begin{tabular}{|c|c|c|c|c|}
\hline & PP & $\mathrm{PH}$ & $\mathrm{HP}$ & $\mathrm{HH}$ \\
\hline$\tau$ & $\begin{array}{c}\text { Coef. } \\
\text { (t-value) }\end{array}$ & $\begin{array}{c}\text { Coef. } \\
\text { (t-value) }\end{array}$ & $\begin{array}{c}\text { Coef. } \\
\text { (t-value) }\end{array}$ & $\begin{array}{c}\text { Coef. } \\
\text { (t-value) }\end{array}$ \\
\hline Intercept & $\begin{array}{c}3.23 \\
\left(27.2^{* *}\right)\end{array}$ & $\begin{array}{c}3.76 \\
(14.7 * *)\end{array}$ & $\begin{array}{c}4.55 \\
(27.5 * *)\end{array}$ & $\begin{array}{c}4.88 \\
\left(25.4^{* *}\right)\end{array}$ \\
\hline$W_{e}$ & - & $\begin{array}{c}-0.154 \\
(-2.87 * *)\end{array}$ & $\begin{array}{c}-0.228 \\
(-6.53 * *)\end{array}$ & $\begin{array}{c}-0.226 \\
(-5.58 * *)\end{array}$ \\
\hline$D$ & $\begin{array}{c}-0.0153 \\
(-4.50 * *)\end{array}$ & - & - & - \\
\hline $\mathrm{R}^{2}$ & 0.428 & 0.234 & 0.613 & 0.536 \\
\hline $\mathrm{N}$ & 29 & 29 & 29 & 29 \\
\hline
\end{tabular}

better visibility to select smaller gaps; in $t_{f}$, the turning trajectory is more smoothly for the entering vehicle to drive enter the RAB, so that it is easier to keep a lower follow-up time; in $\tau$, larger $D$ is easier for circulating vehicles to keep smaller headway. However for $\mathrm{HV}$ compositions, $D$ is not significant in $t_{f}$ and $\tau$. The largest $D$ among these study sites is $44 \mathrm{~m}$, while comparing to the RABs in Europe or America, it is absolutely compact for $\mathrm{HV}$ driving in $\mathrm{RAB}$, so that it does not show the significant influence.

Entry width $W_{e}$ affects $t_{f}$ for all compositions as illustrated in Table 6(b) and $\tau$ for compositions 
including HV as shown in Table 6(c). With a wider entry width, follow-up time $t_{f}$ for entering vehicles decrease since it is easier to enter roundabouts. Regarding HVs of $\tau$, since the physical size of HVs is large, it will make drivers more carefully drive on the circulatory roadway. A wider entry width implies further the curb of entry approach from circulatory roadway where circulating vehicles do not need to pay more attention to the roadside curb, thus the minimum headway of HV decreases.

The dummy of splitter island has influence on $t_{-} P P$ because that if splitter island is placed between entering lane and exiting lane, entering vehicle has no need for paying more attention to opposite exiting vehicle. However, regarding the cases including HVs, no matter whether there is a splitter island or not, the drivers of HVs will enter the RAB carefully.

It also concluded that the geometric elements have different impacts on PC and HV which should be carefully considered for constructing roundabouts with different $\mathrm{HV}$ ratios.

Finally, the gaps estimated by the models are compared with the observed ones. MAPEs are calculated for the validation of estimated data with empirical data only and for validation of estimated data with the mixture of empirical and supplemented data, respectively. The MAPEs for all the compositions and their sample size are summarized in Table 7 and the example of $t_{f_{-} P P}$ and $t_{f_{-} H H}$ are illustrated in Fig.6.

\section{ENTRY CAPACITY AND PCE ESTIMA- TION}

\section{(1) Estimation of entry capacity and PCE by equa- tion}

For estimation of entry capacity, Equation (1) is utilized based on three gap parameters. Probability of composition is calculated by Equation (4a) and (4b).

$$
\begin{gathered}
P_{d c 1 d c 2-d e 1}=P_{d c 1} \times P_{d c 2} \times P_{d e 1} \\
\quad \text { if } \quad d_{i}=H V, P_{i}=H V_{i} ;
\end{gathered}
$$$$
\text { otherwise } d_{i}=P C, P_{i}=1-H V_{i}
$$

For evaluating the impact of $\mathrm{HV}$ on capacity estimation, PCE for $\mathrm{HV}$ on entering flow is calculated by Equation (5).

$$
P C E_{e}=\frac{1}{H V_{e}}\left(\frac{c_{e}\left(0, Q_{r}\right)}{c_{e}\left(H V_{e}, Q_{r}\right)}-1\right)+1
$$

Where, $c_{e}\left(0, Q_{r}\right)$ and $c_{e}\left(H V_{e}, Q_{r}\right)$ are the entry capacity for circulating flow $Q_{r}$ when $\mathrm{HV}$ ratio at the entry approach is 0 and $H V_{e}$, respectively.

Considering the influencing geometry elements of inscribed circle diameter and entry width, two case studies reflecting different geometry designs are hypothesized. One is a Compact-RAB with $D$ equals

\begin{tabular}{|c|c|c|c|c|c|c|c|c|}
\hline \multirow{2}{*}{ MAPE \& $n$} & \multicolumn{8}{|c|}{$t_{c}$} \\
\hline & PP-P & PH-P & PP-H & HP-P & $\mathrm{PH}-\mathrm{H}$ & HH-P & HP-H & $\mathrm{HH}-\mathrm{H}$ \\
\hline$E$. & $8 \%$ & $14 \%$ & $8 \%$ & $14 \%$ & - & - & - & - \\
\hline$n$ of $E$. & 28 & 6 & 8 & 2 & - & - & - & - \\
\hline$E . \& S$. & $8 \%$ & $9 \%$ & $7 \%$ & $8 \%$ & $7 \%$ & $7 \%$ & $7 \%$ & $7 \%$ \\
\hline$n$ of $E . \& S$. & 29 & 29 & 29 & 29 & 29 & 29 & 29 & 29 \\
\hline \multirow{2}{*}{ MAPE \& $n$} & \multicolumn{4}{|c|}{$t_{f}$} & \multicolumn{4}{|c|}{$\tau$} \\
\hline & $\mathrm{PP}$ & $\mathrm{PH}$ & $\mathrm{HP}$ & $\mathrm{HH}$ & $\mathrm{PP}$ & $\mathrm{PH}$ & $\mathrm{HP}$ & $\mathrm{HH}$ \\
\hline$E$. & $6 \%$ & $9 \%$ & $8 \%$ & $4 \%$ & $3 \%$ & $9 \%$ & $5 \%$ & $4 \%$ \\
\hline$n$ of $E$. & 28 & 18 & 23 & 2 & 29 & 27 & 29 & 3 \\
\hline$E . \& S$. & $6 \%$ & $8 \%$ & $8 \%$ & $7 \%$ & $3 \%$ & $9 \%$ & $5 \%$ & $6 \%$ \\
\hline$n$ of $E . \& S$. & 29 & 29 & 29 & 29 & 29 & 29 & 29 & 29 \\
\hline
\end{tabular}
to $27 \mathrm{~m}$ and $W_{e}$ equals to $3 \mathrm{~m}$; the other is a Large-
Table 7 MAPEs with sample size.

$n$ : sample size $\quad E .:$ Estimated gaps $S .:$ Supplemented gaps

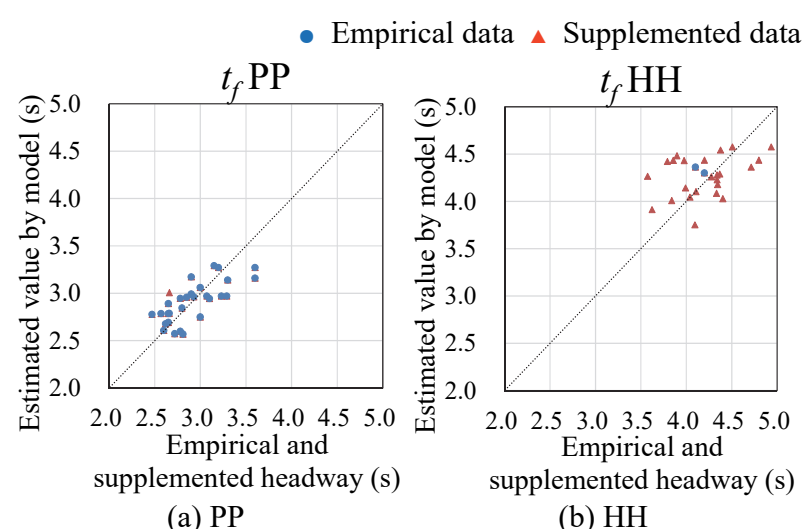

Fig.6 Validation of model for $t_{f}$.

RAB with $D$ equals to $44 \mathrm{~m}$ and $W_{e}$ equals to $6 \mathrm{~m}$.

The entry capacity $\left(C_{e}\right)$ and $P C E_{e}$ of proposed regression models are estimated for Compact-RAB and Large-RAB, respectively, at heavy percentage of circulating flow $\left(H V_{c}\right)$ equals to 0.2. As shown in Fig. 7(a) and (b), the $c_{e}$ s decrease with the $H V_{e}$ increasing, and the $c_{e}$ S of Large-RAB are higher than those of Compact-RAB at the same $H V_{e}$. As for $P C E_{e}$ in Fig. $7(\mathbf{c})$ and (d), it has an increasing trend between 1.4 to 1.8 and the higher $H V_{e}$ are observed increasing more sharply, both of the $P C E_{e}$ ranges are lower than 2.0 proposed by JRM. However, the trends of $P C E_{e}$ by changing $H V_{e}$ are opposite at Compact-RAB and Large-RAB. In Fig. 7(c), it is found that higher $H V_{e}$ results in higher $P C E$ e. It can be considered that the geometry of Compact-RAB is difficult to drive for HVs and more HVs will have stronger effect on entry capacity which result in a higher $P C E_{e}$. Regarding the result of Large-RAB in Fig. 7(d), the HVs can easily drive on the RAB which movement is similar to PCs. Therefore, when $H V_{e}$ increases, the $P C E_{e}$ will decrease.

\section{(2) Estimation of entry capacity and PCE by sim- ulation}

\section{a) Layout of hypothesized Large-RAB}

In order to define the impact of $\mathrm{HV}$ on roundabout entry capacities under various HV percentages, microscopic traffic simulator VISSIM is utilized to simulate the saturated flow for estimating entry capacity. The estimated results of regression model 

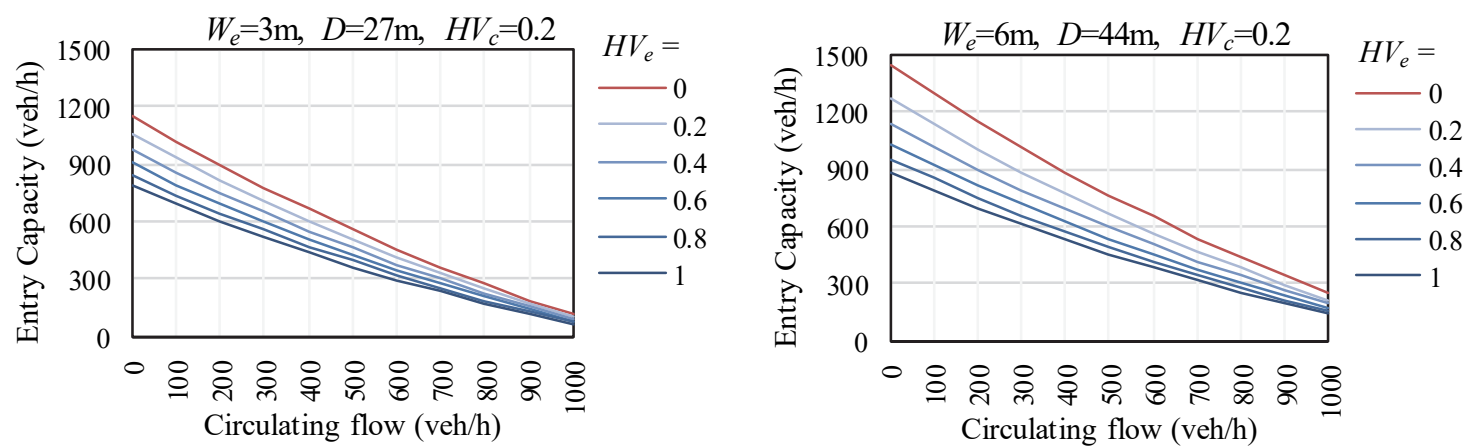

(a) Entry capacity of Compact-RAB

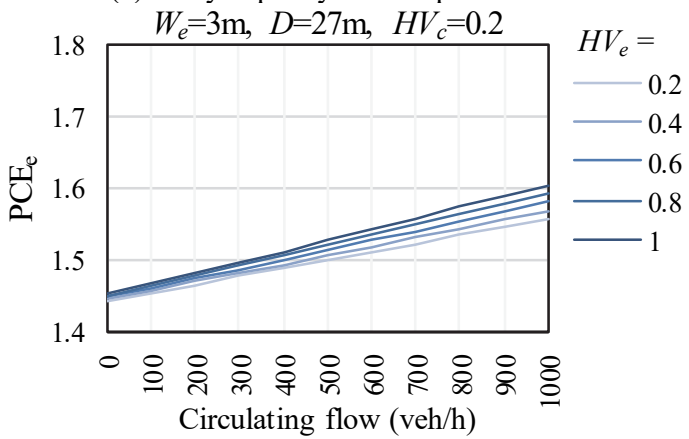

(c) PCE of Compact-RAB

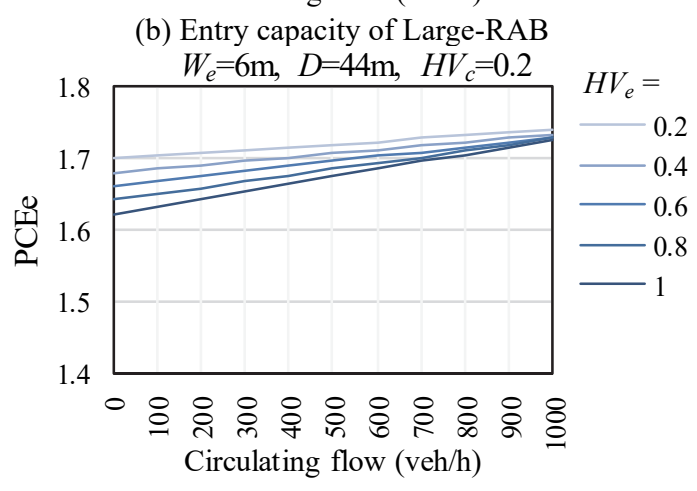

Fig. 7 Entry capacity estimation and $P C E_{e}$ of proposed regression models.

and simulation are compared to verify whether VISSIM could emulate the gap acceptance as same as the real traffic situation. Since the HV size in VISSIM is longer than the situation in Japan, for smoothly estimating the entry capacity in VISSIM, only Large-RAB is adopted for simulation with a geometric layout $\left(W_{e}=6.0 \mathrm{~m}, D=44.0 \mathrm{~m}, d_{s t}=1\right)$. In the simulation, after 900 s of warm-up time, the entry capacity estimated by simulating saturated entering flow then the maximum number of vehicles observed for one hour entering the RAB is regarded as entry capacity in VISSIM.

The width of circulatory roadway and entry approach is $5.0 \mathrm{~m}$ and $3.0 \mathrm{~m}$, respectively. The entry approach with splitter island (Entry-W) is the subjective approach in simulation as illustrated in Fig.8. Reduced speed area is set on circulatory roadway with a mean of desired speed distribution as $20 \mathrm{~km} / \mathrm{h}$. Furthermore, it is set on every entry approach for the deceleration before entering the roundabout with a mean of desired speed distribution as $25 \mathrm{~km} / \mathrm{h}$. Vehicle compositions are set for HVs and PCs by using the default values of VISSIM. Vehicle length of PC is from $3.75 \mathrm{~m}$ and $4.76 \mathrm{~m}$ and that of $\mathrm{HV}$ is $10.22 \mathrm{~m}$. It is noticed that the HV length in VISSIM is rather longer than Japanese situation where vehicle length over $6 \mathrm{~m}$ is considered as HV.

The vehicle turning ratio from Entry-W is following a proportion of left turn ( $L T)$, through $(T H)$, right turn $(R T)$ as $L T: T H: R T=2: 7: 1$. The proportion assigned for traffic flow of Entry-S and Entry- E is set as $Q_{S}: Q_{E}=3: 1$. As for the traffic flows

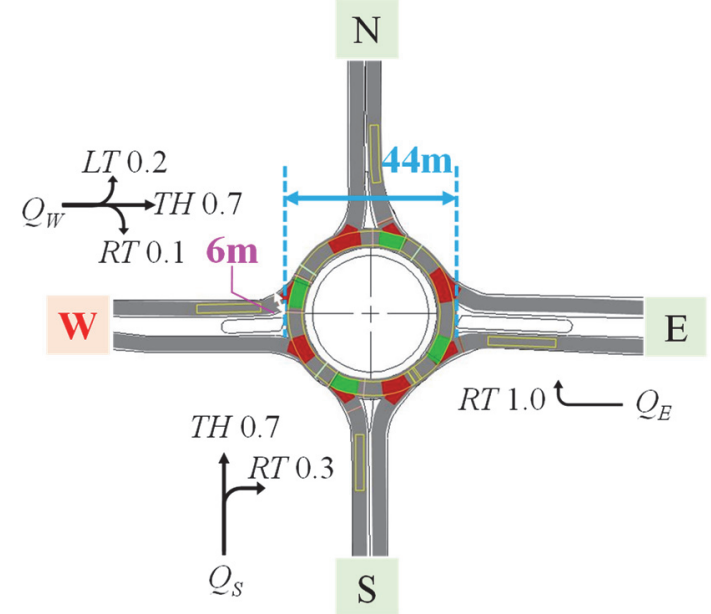

Fig.8 Layout of hypothesized RAB in VISSIM 10.00.

on the circulatory roadway affecting gap acceptance behavior of entry flow at Entry-W, turning movements of $T H$ from Entry-S, $R T$ from Entry-S and $R T$ from Entry-E are considered only. The vehicle turning movement proportion from $Q_{S}$ is $T H: R T=7: 3$ and all the traffic flow of $Q_{E}$ is assigned to $R T$.

\section{b) Calibration of gap parameters}

In order to make simulation results reliable, it is necessary to calibrate gap acceptance and following vehicle behavior of PC and HV. $t_{c}, t_{f}$ and $\tau$ estimated for hypothesized models, are used for calibration targets in simulation. However, since the HV length in VISSIM is approximately $4 \mathrm{~m}$ larger than the Japanese situation, the headway should also be adjusted in VISSIM. Otherwise the critical headway occupied by larger vehicle length would be too small 
for entering vehicle to accept. Thus, vehicle speed is considered for adjusting a new headway target. $15 \mathrm{~km} / \mathrm{h}$ of entering vehicle and $20 \mathrm{~km} / \mathrm{h}$ of circulating vehicle are calculated for the headway, respectively. So that the headway of HV on circulatory roadway and on entering approach should add $0.72 \mathrm{~s}$ and $0.96 \mathrm{~s}$, respectively, for the additional $4 \mathrm{~m}$.

In VISSIM, gap values cannot be input directly thus "safety distance parameters" in Driving Behaviors and "minimum gap time" in Priority Rules are adjusted for reproducing car following behaviors and gap acceptance behaviors, respectively.

\section{c) Scenario settings}

In simulation, the entry capacity estimated by simulating saturated entering flow then the maximum number of vehicle entering roundabout is assumed as its value. The estimated results of regression model and simulation are compared to verify whether traffic simulator VISSIM could emulate the gap acceptance as same as the real traffic situation.

Traffic flows and heavy vehicle percentages are changed for scenarios in VISSIM settings. With regard to the traffic flow input from entries, the subjective Entry-W has to be always saturated. Thus, the traffic flow input of Entry-W " $Q_{W}$ " is $2000 \mathrm{veh} / \mathrm{h}$. The circulating flows from Entry-S and Entry-E affect gap acceptance of Entry-W, which is increased by per $200 \mathrm{veh} / \mathrm{h}$ between 0 to $1000 \mathrm{veh} / \mathrm{h}$ for each scenario. Heavy vehicle percentage is modified for $20 \%$ in circulating flow. Entry capacity are observed for the heavy vehicle percentages changed in entering flow per $20 \%$ between $10 \%$ and $100 \%$.

The traffic flow observed for one hour passing through the "stop line" is regarded as entry capacity in VISSIM. For each scenario, simulation runs for 5 times by changing random seed and the running time period is 4500 s with the first 900 s as warm-up time. Then the average of entry capacity of five runs is calculated as representative entry capacity.

\section{(3) Entry capacity and PCE comparison of hy- pothesized models and JRM}

As shown in Fig.9(a), the entry capacity decreases with the circulating flow increasing, and the entry capacity also decreases when $H V_{e}$ becomes high. Comparison of entry capacities estimated by the entry capacity equation and that estimated by VISSIM indicates that those of VISSIM decrease significantly with the $H V_{e}$ increasing. It is also because the HV length is different from empirical analysis and VISSIM. Therefore, the entry capacity is adjusted by Equation (6) for the vehicle length and considering the $\mathrm{HV}$ percentage.

$$
c_{e}^{\prime}=c_{e}\left(1-H V_{e}\right)+c_{e} \times H V_{e} \times \frac{10 m}{6 m}
$$

Where $c_{e}{ }^{\prime}$ is adjusted capacity; $c_{e}$ is capacity

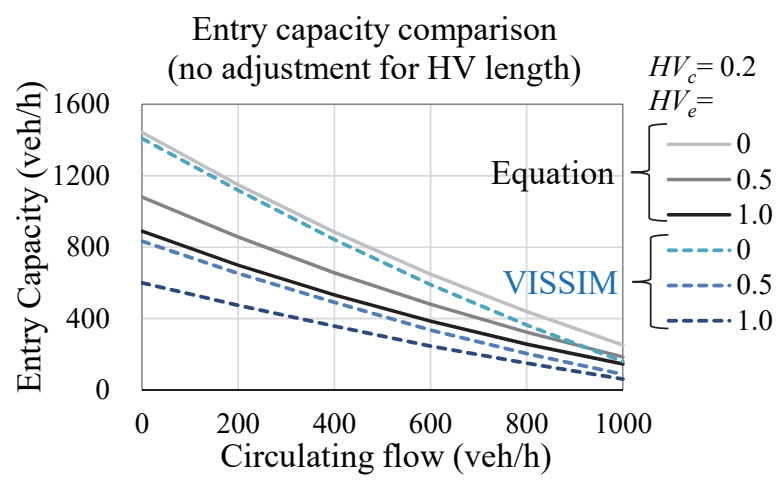

(a) Entry capacity (no adjustment)

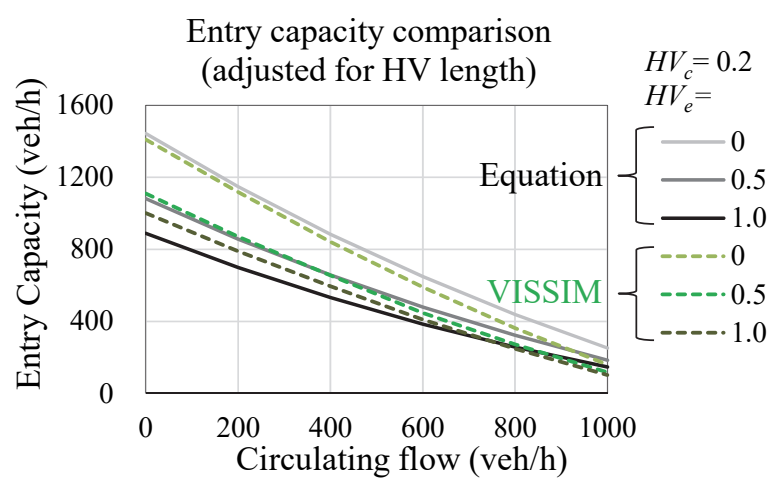

(b) Entry capacity (adjusted for HV length)

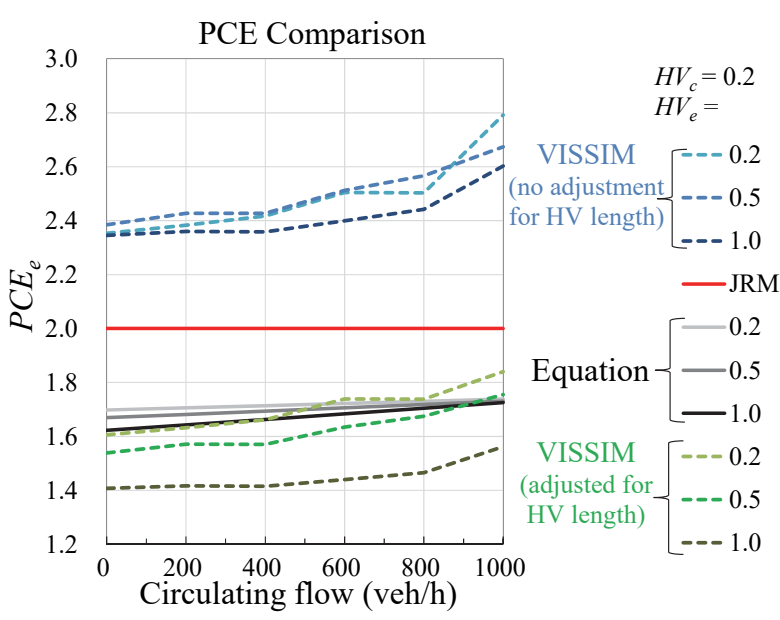

(c) PCE

Fig.9 Comparison of hypothesized models and JRM.

estimated from VISSIM; $H V_{e}$ is heavy vehicle percentage of entering approach.

After adjusting for the HV length, the adjusted capacity of VISSIM becomes closer to the estimated one by equation as shown in Fig.9(b), which can illustrate that the VISSIM can verify the entry capacity estimation of model.

The calculated PCEs by using entry capacity equation and simulation of hypothesized Large-RAB, respectively, are compared with the PCE as suggested value 2.0 in JRM, as shown in Fig.9(c). The PCEs of the hypothesized model is slightly lower comparing to the value of JRM but show a decreasing trend considering the $\mathrm{HV}$ percentage changed in entering flow $\left(H V_{e}\right)$. Due to PCE are considered by both the influence of geometric elements and $\mathrm{HV}$ 
percentage increasing, it is more suitable for estimating entry capacity accurately than by using a constant value. However, the PCE of simulation extremely increased at high circulating flow which is considered not reliable. While for comparing the PCE at low circulating flows, simulation results are considerably close to the hypothesized models, which demonstrates that the simulation can be utilized for the validation of theoretical model, but should be carefully calibrated to the empirical situation.

\section{CONCLUSION AND FUTURE WORK}

In this study, an alternative calculation method for supplementing insufficient empirical data is proposed. Each vehicle composition including heavy vehicle has a multiplier $r$ value for representing the heavy vehicle impact at different positions in a gap acceptance behavior. An adjusting procedure has been proposed for considering the geometric elements on heavy vehicle compositions, so that all the observed data can be fully utilized.

Firstly, the relationship between three gap parameters and geometric elements was analyzed. All the three gap parameters are influenced by inscribed circle diameter $D$, which reveals that the size of roundabout generally determines the entry capacity. Entry width $W_{e}$ affects $t_{f}$ for all compositions and $\tau$ for compositions including HV. With a wider $W_{e}$, it is easier to keep a lower followup time to enter roundabouts; as for the HV of $\tau$. Wider entry width implies farther the curb of entry approach from circulatory roadway where circulating vehicles do not need to pay more attention to the roadside, thus the $\tau$ decreased.

Secondly, passenger car equivalents at hypothesized roundabouts with different geometries are estimated by regression model and simulation, respectively. $\mathrm{PCE}_{\mathrm{e}}$ ranges between 1.4 and 1.8 with different $H V_{e}$ and circulating flow, which is smaller than 2.0 proposed by Japanese Roundabout Manual. It is indicated that roundabout where geometric layout is easy for HV to enter, the entry capacity could be higher comparing to the manual.

In the future work, more data at other roundabouts with various geometries should be observed, especially the ones with high heavy vehicle percentage. Moreover, it is required to be clarify how the behaviors of different heavy vehicles such as buses and trucks are different at roundabouts. Furthermore, in the simulation analysis, vehicle length of heavy vehicles is defined as $10.22 \mathrm{~m}$ as the default value in VISSIM 10.00. Since it will effect headway parameters which are observed by simulation, it is preferable to adjust it to the value observed in Japan.

ACKNOWLEDGMENT: The authors are very grateful to Dr. Nobuto Kanbe of Oriental Consultants Co., Ltd. for his support in providing data necessary for this research. This work was supported by JSPS KAKENHI Grant-in-Aid for Scientific Research (B), Grant Number 16H04426. The authors also would like to thank Road Maintenance Department of Aichi Prefecture for providing the video data of the roundabout in Aisai-City.

\section{REFERENCES}

1) Transportation Research Board, Highway Capacity Manual 6th Edition. Washington D.C, 2016.

2) Japan Society of Traffic Engineers: Roundabout Manual, 2016. (in Japanese)

3) PTV Planung Transport Verkehr AG: VISSIM 10.00, 2017.

4) Lee, C.: Passenger car equivalents for heavy vehicles at roundabouts: estimation and application to capacity prediction, Proceedings of the 93rd Transportation Research Board Annual Meeting, Washington, D.C., 2014.

5) Goto, A., Kang, N., Nakamura, H. and Mashima, K.: Passenger car equivalent of heavy vehicles for roundabout entry capacity estimation, Infrastructure Planning, Vol. 2, No. 6, pp. 11-19, 2016. (in Japanese)

6) Kimber, R.: Traffic Capacity of Roundabouts, Transportation and Research Laboratory, Laboratory Report LR942, Crawthorne, Berkshire, U.K., 1980.

7) Kanbe, N., Zhang, X., Nakamura, H. and Odaka, S.: A roundabout entry capacity estimation model considering the impact of geometric elements, Journal of Japan Society of Civil Engineers, Ser.D3, Vol. 74, No. 5, pp. I_1411-I_1418, 2019. (in Japanese)

8) Zhao, Y., Zhang, X., Alhajyaseen, W. and Nakamura, H.: Modeling the impacts of heavy vehicle and geometry on roundabout entry capacity, Transportation Research Board, 2018.

9) Suzuki, K. and Nakamura, H.: TrafficAnalyzer - the integrated video image processing system for traffic flow analysis, Proceedings of the 13th World Congress on Intelligent Transportation Systems, London, 2016.

10) Raff, M. S. and Hart, J. W.: A volume warrant for urban stop signs, Traffic Engineering and Control, pp. 255-258, 1950.

11) Japan Road Association: Explanation and Description of Road Structure Ordinance, 2016. (in Japanese)

(Received February 22, 2019)

(Accepted August 26, 2019) 